\title{
PLANNING AND SCHEDULING BRIDGE GIRDERS FABRICATION THROUGH SHOP- FLOOR OPERATIONS SIMULATION
}

\author{
Monjurul Hasan ${ }^{1}$, Ming Lu${ }^{1}$, and Ken Bird ${ }^{2}$ \\ ${ }^{1}$ University of Alberta, Edmonton, Alberta, Canada \\ ${ }^{2}$ Supreme Steel, Acheson, Alberta, Canada
}

\begin{abstract}
In modular and offsite construction, structural components are prefabricated in a fabrication shop resembling a manufacturing plant in order to accelerate field construction processes. However, the dynamic nature of such fabrication operations often demands frequent adjustments to original production plans so as to fit actual project start-finish schedules in terms of completion dates and budgets and accommodate changes in design details. It is a daunting task to minimize disruptions to ongoing workflows while realizing high efficiency in utilization of shop production resources. In reality, such situations constantly press production manages to take prompt decisions without having analytical decision support in exploring available options, potentially resulting in loss of productivity on the shop floor and missed deadlines. This research introduces a structured approach to communicating shop-floor operations simulation at various management levels. The paper focuses on the representation of project schedules and production plans resulting from simulation in straightforward, role-specific "bar charts". The applicability of the proposed approach is demonstrated with a case in the setting of a steel girder fabrication shop.
\end{abstract}

\section{Introduction}

Advances in engineering technology and requirements for sustainable development are main drivers for changes and innovations in the current construction industry. The paradigm shift to modular and offsite construction is moving conventional field construction efforts into the controlled environment of an offsite manufacturing facility (Pasquire et al., 2002). This lends a significant advantage to execution of fast-paced construction projects, making construction schedules better organized, shorter, and less susceptible to environmental factors, while substantially reducing the number of skilled craft workers on site and improving quality and safety performances (Lu and Liska, 2008). Despite all the advantages of offsite construction, planning and scheduling operations at offsite production facilities still present distinctive challenges due to one-of-akind product design, concurrent execution of multiple projects, and finite limits of skilled trades and space available in a fabrication shop (Liu and Lu, 2018). Herein, shop production planning is similar to planning a conventional project in the field, which entails establishing the workflow logic between all the jobs and allocate sufficient resources to complete planned jobs within limited budgets and finite timeframes (Halpin and Riggs, 1992). In fact, planning made-to-order operations in a typical fabrication shop is no lesser a challenge than planning construction operations in the field, subject to varied product designs from different projects, limited skilled laborers, finite space resources and client-imposed deadlines. Thus, a well-formulated production plan for a structural steel fabrication shop is vital to deliver bespoke structural components on site by respective deadlines while keeping production costs within budget limits (Song and AbouRizk, 2006). The general process of such planning process is illustrated in Figure 1.

This research highlights a unique planning problem in bridge steel girder fabrication to illuminate the reasons why the identified problem does not lend it well to existing solutions for construction planning. Main characteristics of the offsite fabrication problem are summarized as follows:

- A lot of variations: This shop floor problem features variations in product design specifications and fabrication processes; a product goes through a unique process. The basic lean principle of reducing variation (i.e. six sigma) is not applicable (Dedhia, 2005; Nakhai and Neves, 2009).

- Product sequencing is key: The problem is tightly constrained by resource use (labor intensive), space, and material handling systems - similar to established problems in construction planning. Nonetheless, product sequencing plays a crucial part in shop production planning, 


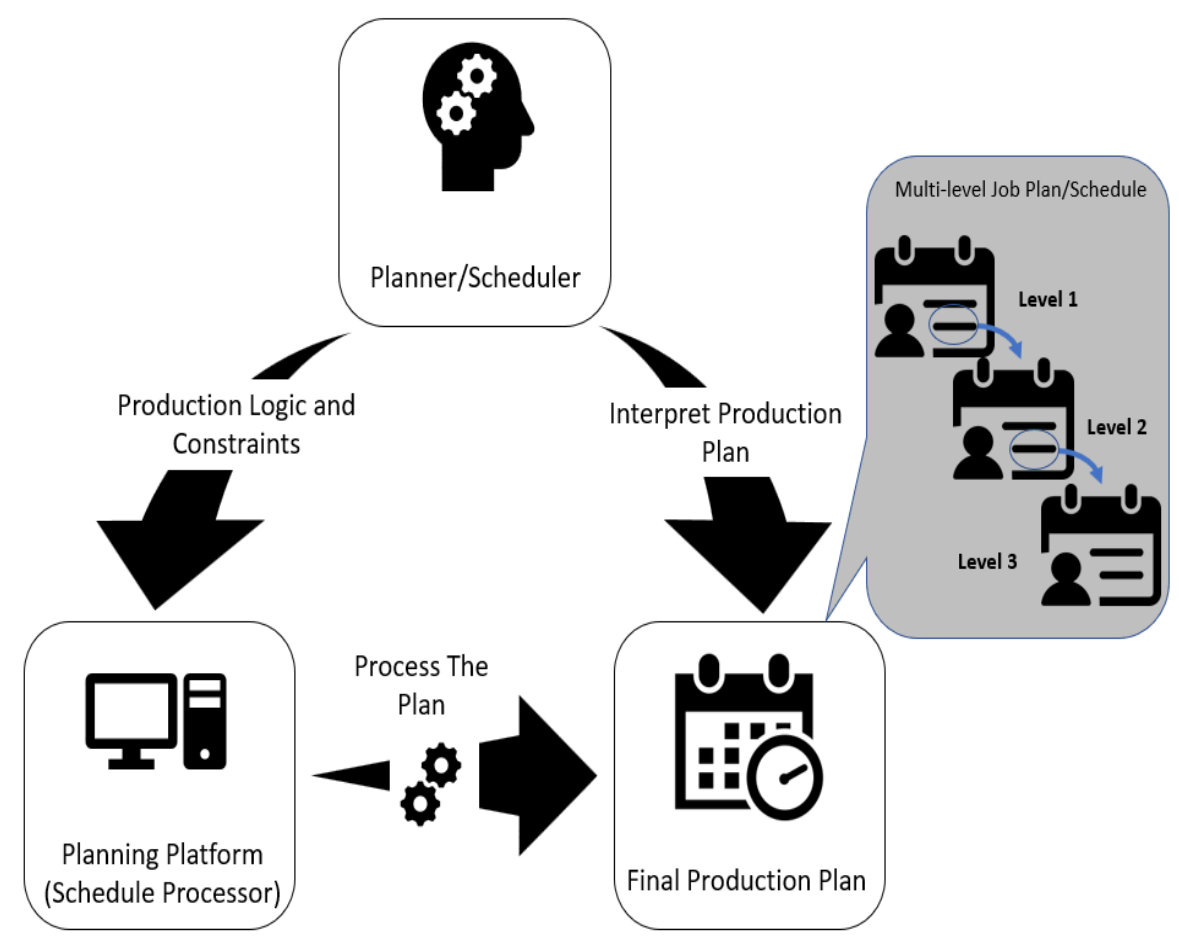

Figure 1Planning process of any typical offsite steel bridge girder fabrication shop

dictated by construction technology (splicing) and site demand (delivery timing.)

- $\quad$ Site client demands lean: The site demand can be a hard constraint (just in time delivery is demanded as there is no buffer space on site; late delivery penalty would be imposed due to idling field crews and project completion delay; early delivery penalty would incur due to laydown yard cost and extra material handling cost).

- Shop processing demands lean: The inventory cost and extra material handling cost in the shop are significantly high due to size of product and space limit. So, once production starts, the sequence of products is not flexible to change.

- Avoid idling expensive resources: The trades and assets in the shop are limited resources, expensive; hence, it is critical to have workface plan formulated beforehand, which effectively guides allocating work to trades/stations while ensuring utilization of resources as fully as practically possible.

- No cost-effective analytical tool: It is crucial to have a simulation model to assist project managers in evaluating the impact of site demand changes, the impact of resources/space provisions.

In this paper a simulation-based approach is presented for project scheduling and production planning at a structural steel fabrication shop, considering major constraints typically imposed on a fabrication facility, which simultaneously serves field construction needs from multiple projects. Particular emphasis is placed on representing and interpreting simulated production plans in customized schedules of various details in an attempt to cater for the needs of different stakeholders involved at various management levels. The applicability of the proposed approach is demonstrated with a case in the realworld setting of a steel girder fabrication shop.

\section{Problem Statement}

\section{Importance of Planning}

Planning is the key to keep workforce engaged in a productive production process (AbouRizk and AbouRizk, 2009). Project planning includes work package breakdown, definition, organization and allocation down at the construction site or shop floor level. Project Management Institute (PMI) defines work package (WP) as the lowest level Work Break Structure (WBS) used to group the activities, where work is scheduled and estimated, monitored, and controlled (PMI, 2017). Constriction Owners Association of Alberta (COAA, 2013) promotes "Workface Planning" as the best practice for the success of any construction project, which is "the process of organizing and delivering all elements necessary, before work starts, to enable craft persons to perform quality work in a safe, effective and efficient manner".

To ensure a worker's uninterrupted process, it is always crucial to ensure that required raw materials, detailed fabrication design, and equipment or tools are available on site, at the right time. At the same 
time, to deliver the highest productivity, a worker must be informed before starting the work on how to structure the day, which milestone to reach, plus an order of time events to accomplish those milestones (Hendricson, 2008). Therefore, a good plan is not just limited to making all tasks organized but also depends on effective communication of defined scope and content (Warner, 1989).

A good work plan can only be effective if it is expressed in the form of a well-organized schedule addressing specific needs relevant to particular stakeholders. Then, the individual worker's job schedule needs to be linked with project resource allocation schedule, resulting in a flawless work plan (Ahuja et al., 1984). At the same time, the work plan needs to be role-specific, contain no redundant information and straightforward to the worker or manager to act on. If any change emerges at any stages of the project lifecycle, that change should be well reflected in every level of schedule in both ways of the plan structure: bottom up and top down. The ensuing sections will illustrate good practices in (1) project planning and scheduling and (2) work planning and communication using a girder fabrication shop which services multiple bridge construction projects. As an example, Table 1 below summarizes requirements for different levels of plans and schedules for maintaining operation flow, execution motoring and project control in bridge girder fabrication.

Table 1Project schedule required for different management functions.

\begin{tabular}{|l|l|l|}
\hline Role & $\begin{array}{l}\text { Plan } \\
\text { Required }\end{array}$ & Responsibility \\
\hline $\begin{array}{l}\text { Program } \\
\text { Manager }\end{array}$ & $\begin{array}{l}\text { Project } \\
\text { Schedule }\end{array}$ & $\begin{array}{l}\text { All projects } \\
\text { owned by the } \\
\text { company }\end{array}$ \\
\hline $\begin{array}{l}\text { Facility/Shop } \\
\text { Manager }\end{array}$ & $\begin{array}{l}\text { Production } \\
\text { Schedule }\end{array}$ & $\begin{array}{l}\text { All projects under } \\
\text { one facility }\end{array}$ \\
\hline $\begin{array}{l}\text { Shop } \\
\text { Superintendent }\end{array}$ & Work plan & $\begin{array}{l}\text { Work plans for } \\
\text { individual trades } \\
\text { and workstations } \\
\text { in the shop }\end{array}$ \\
\hline Trade & To do list & $\begin{array}{l}\text { Work on different } \\
\text { work packages }\end{array}$ \\
\hline
\end{tabular}

\section{Challenges in Bridge Girder Fabrication Planning}

Bridge girder fabrication processes are as tightly constrained as field erection of structural steel with regards to resource use, space, and safety. Each girder piece has a similar appearance but is indeed one-of-a-kind structural element with special features (such as shop splice, field splice, stiffeners, studs, number of drill holes, weld thickness, etc.) These features play a vital part in dictating the specification of work packages and processing sequences for each girder to go through workstations on the shop floor.

During the pre-bidding stage, the upper-level program schedule (timeline for different projects to be handled by the shop) is established first by estimating work content of jobs associated with each unique product (girder). The production efforts (in labor-hours) associated with processing, handling and assembling the individual component are calculated. This labor-hours estimate based on detailed material takeoff is further assessed against the existing shop production capacity prior to determining final budgeted labor-hours and project duration. The current practice relies on the use of critical path scheduling to establish activity predecessor relationships and adapt all the constraints in planning the fabrication program. Furthermore, this program schedule can be adjusted considering the client's deadline and shop resource (journeyman, workstations, machinery, etc.) constraints in identifying the time windows for the fabrication shop to handle particular jobs (Liu and $\mathrm{Lu}, 2018$ ). Afterward, this schedule is passed on to the shop operation planner/manager with start and finish milestones specified for major work packages, subject to which, detailed activity by activity operation schedule is created and communicated to the shop floor operations personnel. In the beginning, with defined work content, the shop production planner is responsible for breaking down work packages into sufficient detail ready for execution in the shop (Hu and Mohamed, 2014). Therefore the shop production planner assigns resources on each activity in a project scheduling platform (e.g., Microsoft Project, P6) and defines activity predecessor relationship one by one.

Shop floor operations schedule consists of repetitive workflows to be performed on non-uniform work units (girders). The mainstream planning tool of Critical Path Method (CPM) represents activity breakdown and predecessor relationships in the form of Activity on Node (AON) diagram, which has proven to be cumbersome and ineffective, potentially resulting in an extra-large, overwhelmingly complex AON network model in representation of repetitive workflows performed on non-uniform work units (Hyari and El-Rayes, 2006). Again, performing such scheduling tasks can be tedious, usually takes time and largely depends on the planner's experience and expertise (Song and AbouRizk, 2006). The scheduler is also responsible for representing schedules in the interest of different stakeholders (e.g., Journeyman, shop floor manager, station manager). In reality, the scheduling process becomes a daunting task, updating obtained schedules in a short turn-around time would be practically infeasible when a need to change operation logic and resource constraints arise. In reality, it is not realistic to keep in halt the production until the CPM schedules are updated. There is not 
sufficient time to update CPM schedules at different levels and probe "what-if" alternative scenarios in resequencing job production and generating an updated set of jobs (to do list for the trades).

To tackle the above-identified limitations, this research study proposes a simulation enabled job planning approach. The simulation model is established based upon the three-tiered methodology proposed by $\mathrm{Lu}$ et al. (2019). In the case study, the Simplified Discrete Event Simulation Approach (SDESA) is used ( $\mathrm{Lu}, 2003)$ as a platform for dynamic and resource-constrained process mapping and simulation purpose.

\section{Simulation-Based \\ Planning Scheduling}

and

To adapt the process-interaction simulation paradigm to better cater to construction simulation needs and simplify construction operations modeling, Lu (2003) formalized the simplified discrete-event simulation approach (SDESA). It is an activity-based simulation method, which mimics the common practice of using CPM in construction planning but requires less modeling efforts inadequately representing complicated construction operations. It is important to note by SDESA the processing sequence of each activity/job is prioritized by first-in first-out rule. Thus, the start time of any activity is delayed until demanded resources are available and other logical conditions as specified are satisfied.

SDESA was enhanced further resulting in the development of a generic process mapping and simulation methodology for integrating site layout and operations planning in construction. Since its introduction, SDESA has been successfully implemented in many cases for planning and academic research purposes. For instance, it was used to model the process of erecting the prefabricated structural elements using cranes in the construction of the steel structure of a stadium ( $\mathrm{Lu}, 2009)$ and to model the operations of installing the precast deck segments considering site constraints of limited site space and logistics on a precast viaduct construction project in the real world (Chan and Lu, 2008).

\section{Process Flow of Steel Girder Fabrication}

Steel plates of different dimensions and grades are transformed into steel girders as per engineering design in the constrained space of the fabrication shop. The fabrication operation mainly consists of the following main steps or work packages (WPs): (1) receiving plates, (2) flanges preparation, (3) web preparation and (4) stiffener preparation, (5) assembling girder by fitting and welding flanges to web, (6) stiffener fitting and welding, (7) studding, (8) field splicing, (9) sandblasting and finishing. The logical interdependencies among these WPs are shown in Figure 2 in the form of AON diagram.

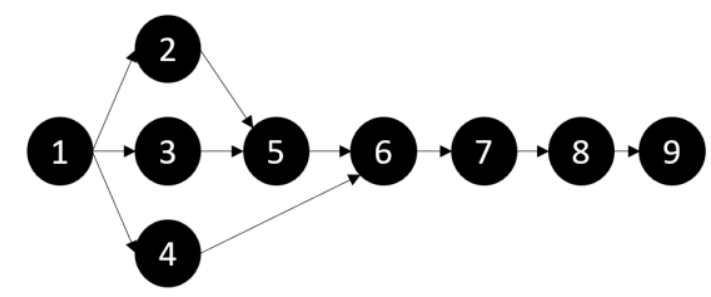

Figure 2 Typical Steel girder fabrication process cycle

The simulation model developed in this study is based upon a similar strategy for the real-world abstraction of workflows of the fabrication shop ( $\mathrm{Hu}$ and Mohamed, 2014). The top tier interface of the applied three-tier modeling architecture of the SDESA model allows the modeler (being production planner) to change job processing order and quantities of finite resources available to the shop, without the need of expertise in computer programming and simulation modeling.

This paper takes advantage of the developed model of the steel bridge girder fabrication shop, as changing model parameters and updating the simulation can be easily achieved given the flexibility offered at the top tier of the simulation model. Schedules in support of multiple management functions are generated from the simulation.

\section{Various Management-Function Schedules}

For steel bridge girder fabrication, the operation schedule for one particular girder consists of nine WPs (Figure 2); which can be elaborated into a total of eighty-nine fabrication activities processed in the shop floor simulation with over one hundred technology constrained precedence relationships plus even more implicit resource constrained precedence relationships. In practice, one project consists of multiple girder lines; and each girder line is made up of several girders. In addition, the shop floor needs to handle multiple bridge projects simultaneously in a limited timeframe. So, if the total number of bridge project one shop needs handle is, $n$ and the total girder lines and associated girders in each line become, $l_{i}$ and $m_{j}$ respectively, then the total amount of activities $(\mathrm{Na})$ one shop manager needs to account in planning is estimated by Eq. 1:

$$
N a=\left(n l_{i} m_{j}\right) \times 89
$$

Hence, it is not practical to apply CPM (P6 or MS Project) to handle a great quantity of activities along with inter-activity relationships for shop-floor operations planning and scheduling.

Here, different stakeholders have different perspectives with respect to planning and schedule of this fabrication shop. The fabrication program manager is mainly interested in tracking the number of projects he or she is handling along with progress on each. The fabrication shop manager under the 
program manager is concerned with sequencing and completion times on each girder line and progress on associated girders. The floor station superintend needs to know which girder arrives at the station at what time and the welder (trade) needs to know when he needs to perform welding on which girders (to do list), at which stations. These multi-levels of schedule representation are further explained in ensuing paragraphs with an example case of shop splicing (WP8).

Shop splicing is one critical fabrication stage involving heavy equipment use and demanding sufficient shop floor space for safety. Hence, two adjacent girders in the same girder-line are placed together in the same way as they would be placed in the field in order to confirm the accuracy of connection details (Figure 3). Suppose the shop is handing just one girder line consisting of three girders: G1A, G1B, and G1C as shown in Figure 3. Here, G1A and G1C need to be spliced just once on one end, but G1B needs to be spliced twice on both ends. Thus, the production logic is presented in the flow chart shown in Figure 4.

Now, assuming the shop can handle one splicing operation at a time, there should be two adjacent girders of the same girder line ready for splicing trial assembly need to be ready at the same time. So, girder G1A and G1B will be spliced together at first, and then in the second round, G1B and G1C will be spliced together. Note, each splicing job (WP8) includes nine unique activities to be performed by a crew of two journeymen ( $\mathrm{J} 1, \mathrm{~J} 2$ or $\mathrm{J} 2, \mathrm{~J} 3$ ) on the individual girder. Here, the shop manager's interest is mainly to track the progress of individual girders. Whereas, the splicing station superintendent needs to track all the activities occurring on the splicing stations. These two schedules of different levels are generated from the simulation and presented in Figure 5. Besides, Figure 6 shows the trade-specific project schedule, which includes job start-finish times and the location and type of each job to be conducted by each journeyman. Ideally, such different plans for different management functions can be automatically produced from the simulation model.

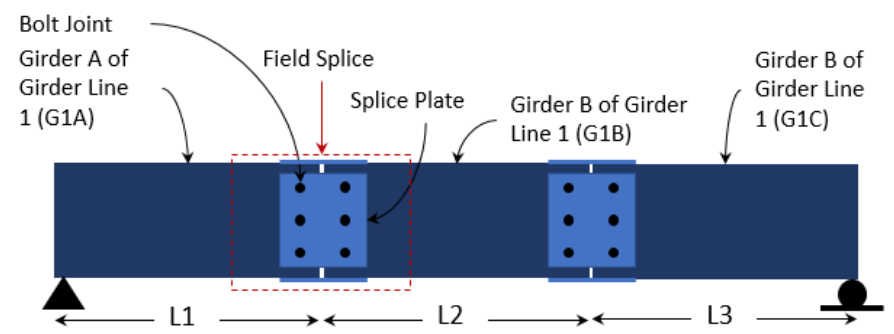

Figure 3 Field splice of a typical Steel plate girder.

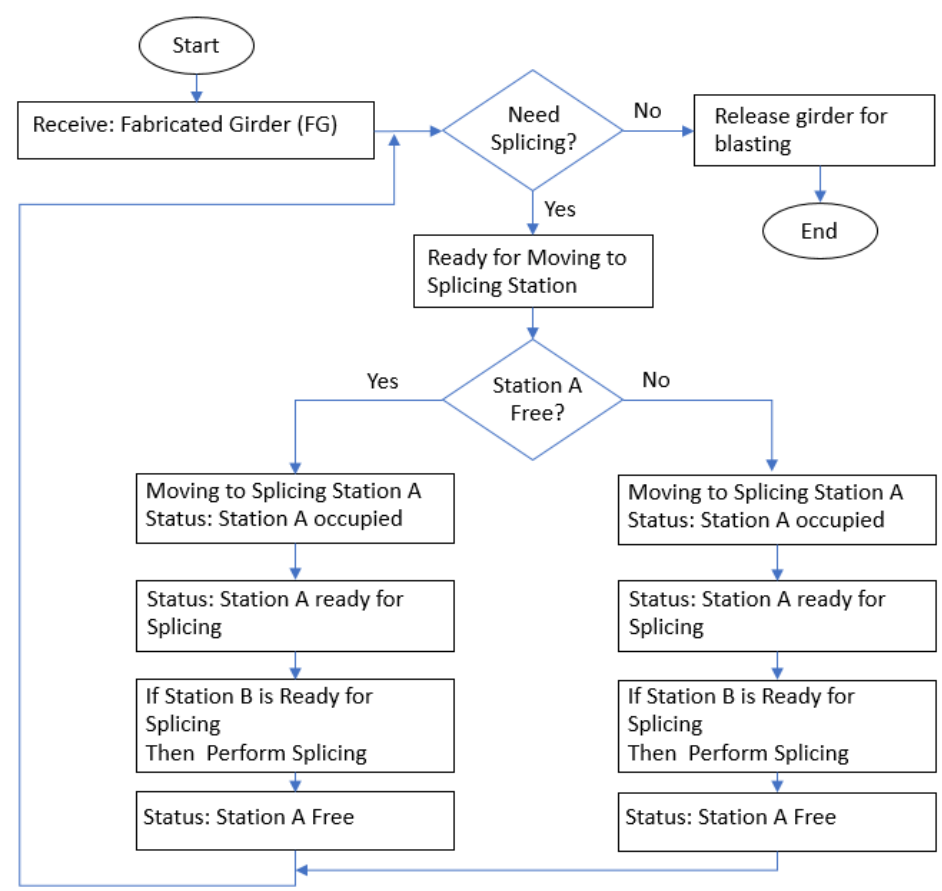

Figure 4 The middle tier of the workflow model: operation logic for field splice 


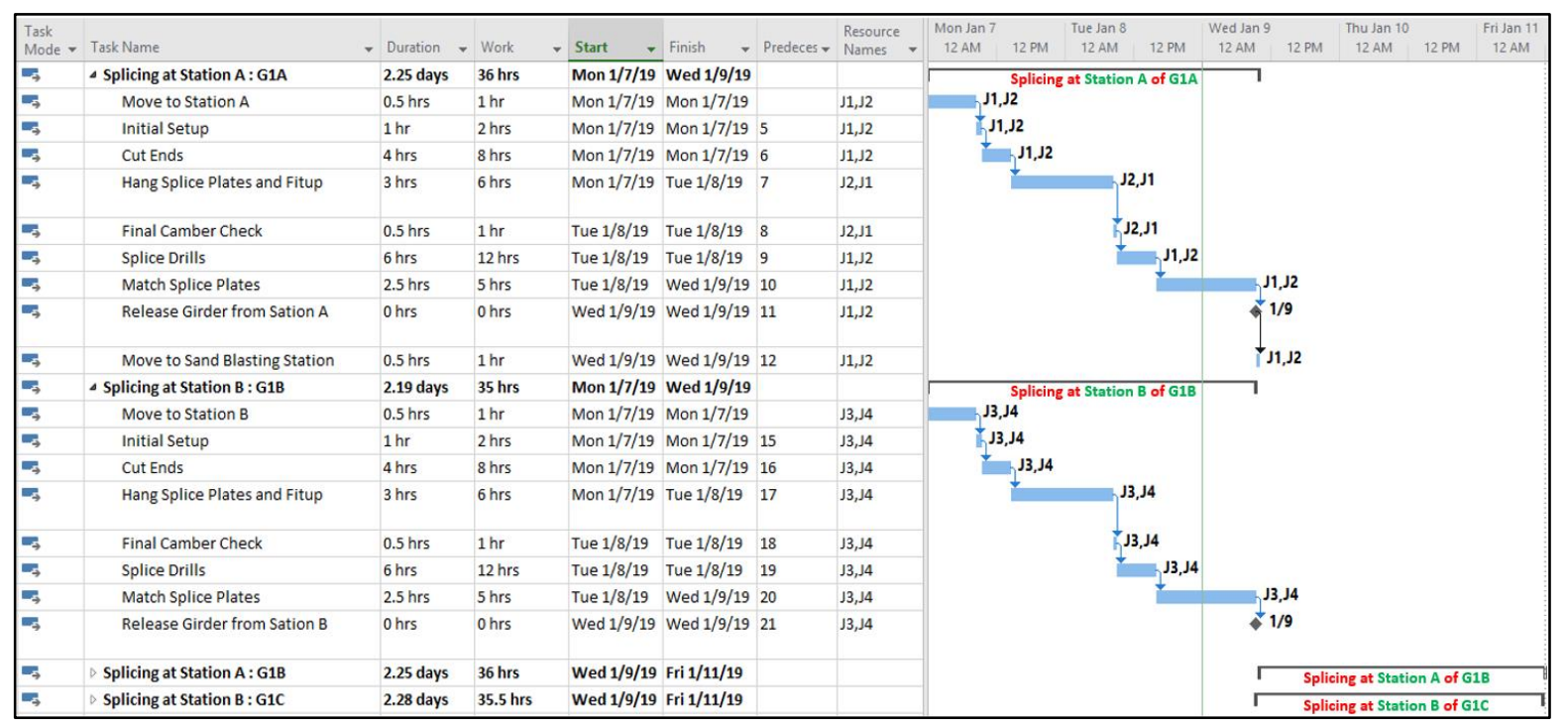

Figure 5 Schedule for the shop production/fabrication manager.

\begin{tabular}{|c|c|c|c|c|c|c|c|c|c|c|}
\hline \multirow{2}{*}{ Resource Name } & \multicolumn{2}{|r|}{ Mon $\operatorname{Jan} 7$} & \multicolumn{2}{|r|}{ Tue Jan 8} & \multicolumn{2}{|r|}{ Wed Jan 9} & \multicolumn{3}{|c|}{ Thu Jan 10} & \multirow{2}{*}{$\begin{array}{r}\text { Fri Jan } 11 \\
12 \mathrm{AM}\end{array}$} \\
\hline & 12 PM & $12 \mathrm{AM}$ & $12 \mathrm{PM}$ & $12 \mathrm{AM}$ & $12 \mathrm{PM}$ & $12 \mathrm{AM}$ & 12 PM & $12 \mathrm{AM}$ & $12 \mathrm{PM}$ & \\
\hline Journeyman 1 & & \multicolumn{3}{|c|}{ Splicing at Station A : G1A } & & & \multicolumn{4}{|c|}{ Splicing at Station B : G1C } \\
\hline Journeyman 2 & & \multicolumn{3}{|c|}{ Splicing at Station A : G1A } & & & \multicolumn{4}{|c|}{ Splicing at Station B : G1C } \\
\hline Journeyman 3 & & \multicolumn{3}{|c|}{ Splicing at Station B : G1B } & & & \multicolumn{4}{|c|}{ Splicing at Station A : G1B } \\
\hline Journeyman 4 & & \multicolumn{3}{|c|}{ Splicing at Station B : G1B } & & & \multicolumn{4}{|c|}{ Splicing at Station A : G1B } \\
\hline
\end{tabular}

Figure 6 Trade specific for splicing job.

\section{Case Study}

A case study was conducted on a steel bridge fabrication shop located near Edmonton, Alberta. The girder configuration is shown in Figure 7. The SDESA shop-floor workflow model -which corresponds with the middle tier in the proposed simulation modeling framework-, was developed according to the shop space configuration, resource use, and availability constraints. Simulation logic was then face validated by domain experts involved in the partner company. It is worth mentioning this study was the initial attempt to generate the project plan through the bottom-up approach (Activity Level: shop floor activity under individual work package < Work Package Level: work packages under each girder < Project Level: all the girders in a project < Program Level: all the projects under the same program). The model's logic was carefully validated through tracing computing details in simulation step by step. Thus, only constant values for activity times were used in scheduling which was provided by shop manager), instead of collecting sample data and defining statistical distributions.

The case study consisted of a total of 6 individual girders making up three girder lines on one bridge. So, as according to Eq. 1, the shop manager is responsible to plan for five hundred thirty-four activities by tackling more than six hundred technological constraints. Plotting AON for such activities considering all resource and technological constraints in any existing CPM tool to produce project schedule is practically infeasible. SDESA in this case basically provides a cost-effective alternative to produce this enormous bar chart like schedule with one click effort.

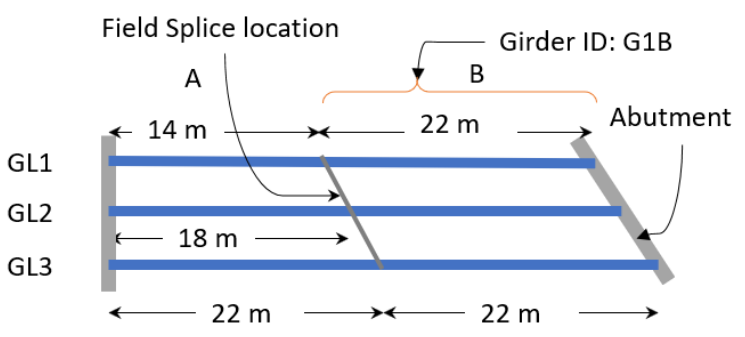

Figure 7 Girder configuration for case study project

In this case study, all the girders were classified into four design types based on girder features (i.e., length, depth, stiffener quantity and locations, field splice type). The same simulation model was then 
used to evaluate shop performances in various what-if scenarios for formulating shop production plan by changing the top tier console only. Attributes (1. length, 2. weight, 3. no of required field-splice) of each girder were assigned in the computer platform accordingly. This top tier console also allows arranging for the fabrication order of the girders in a visual way. In this case, both girders of the same girder line (GL) are fabricated as in the order of A B. Processing order between different GL is changed as part of what-if analysis in order to find the most efficient plan. Simulation results were used to identify the optimum number of crews and the best fabrication order of the girder lines. Results from simulation experiments are given in Table 2, which would help the production meager to decide the number of crews and the production sequence.

For this case, if the production manager's objective is to minimize the total man-hours spent in this project, he or she can choose the production sequence GL1 GL2 - GL3 with five journeymen engaged in the production process (ID 5 of Table 2). Whereas, if there is a deadline to meet, an alternative solution can be considered. Once the job processing sequence along with appropriate resource allocation is determined, project managers simply extract all the necessary plans from the simulation result in the form of customized schedules for various management functions. A screenshot directly taken from SDESA showing start to finish for all the activities in the simulation is shown in Figure 8. It is worth mentioning the bar chart schedule in itself can be overwhelming for effective communication even if the demonstration case is simplified. Considering a realistic setting for the fabrication shop investigated, in which the number of projects (identical) is three (3), the number of girder lines in each individual project is ten (10), and the number of girders in each line is five (5), the total number of activities to be scheduled in the simulation is at least 13,350 based on Eq. (1). One major research contribution is to interpret the bar chart resulting from simulation to the need of different decision makers involved at various management level.

Figure 9 shows the program level schedule (startfinish time for individual girder for the case project) extracted from the simulation model. The work plan for a particular station in the shop can also be generated. Material receiving deadline for each girder is shown in Table 3 as an example. Besides, a to-dolist for a particular worker (trade) can also be generated. Table 4 presents the activity by activity work schedule for Journeyman ID 1.

Table 2 Experimentation results with fabrication shop model

\begin{tabular}{|l|l|c|c|c|c|}
\hline ID & Job Sequence & Journeyman No. & Man hours & Utilization Rate & Project Duration \\
\hline 1 & GL1 - GL2 - GL3 & 9 & 1578 & $59.06 \%$ & $175 \mathrm{hr}$. \\
\hline 2 & GL1 - GL2 - GL3 & 8 & 1450 & $62.24 \%$ & $182 \mathrm{hr}$. \\
\hline 3 & GL1 - GL5 - GL2 & 7 & 1425 & $65.36 \%$ & $204 \mathrm{hr}$. \\
\hline 4 & GL1 - GL2 - GL3 & 6 & 1363 & $68.32 \%$ & $227 \mathrm{hr}$. \\
\hline 5 & GL1 - GL2 - GL3 & 5 & 1339 & $68.22 \%$ & $267 \mathrm{hr}$. \\
\hline 6 & GL1 - GL2 - GL3 & 4 & 1365 & $68.24 \%$ & $341 \mathrm{hr}$. \\
\hline 7 & GL1 - GL3 - GL2 & 5 & 1344 & $69.14 \%$ & $270 \mathrm{hr}$. \\
\hline
\end{tabular}

Table 3 Raw material delivery schedule (schedule for superintendent)

\begin{tabular}{|c|c|}
\hline Collecting Raw Plates for Girder & Material Delivery Date (Job start date: Fri 01/11/19) \\
\hline G1A & 11 January 19 \\
\hline G1B & 15 January 19 \\
\hline G2A & 17 January 19 \\
\hline G2B & 24 January 19 \\
\hline G3A & 31 January 19 \\
\hline G3B & 6 February 19 \\
\hline
\end{tabular}




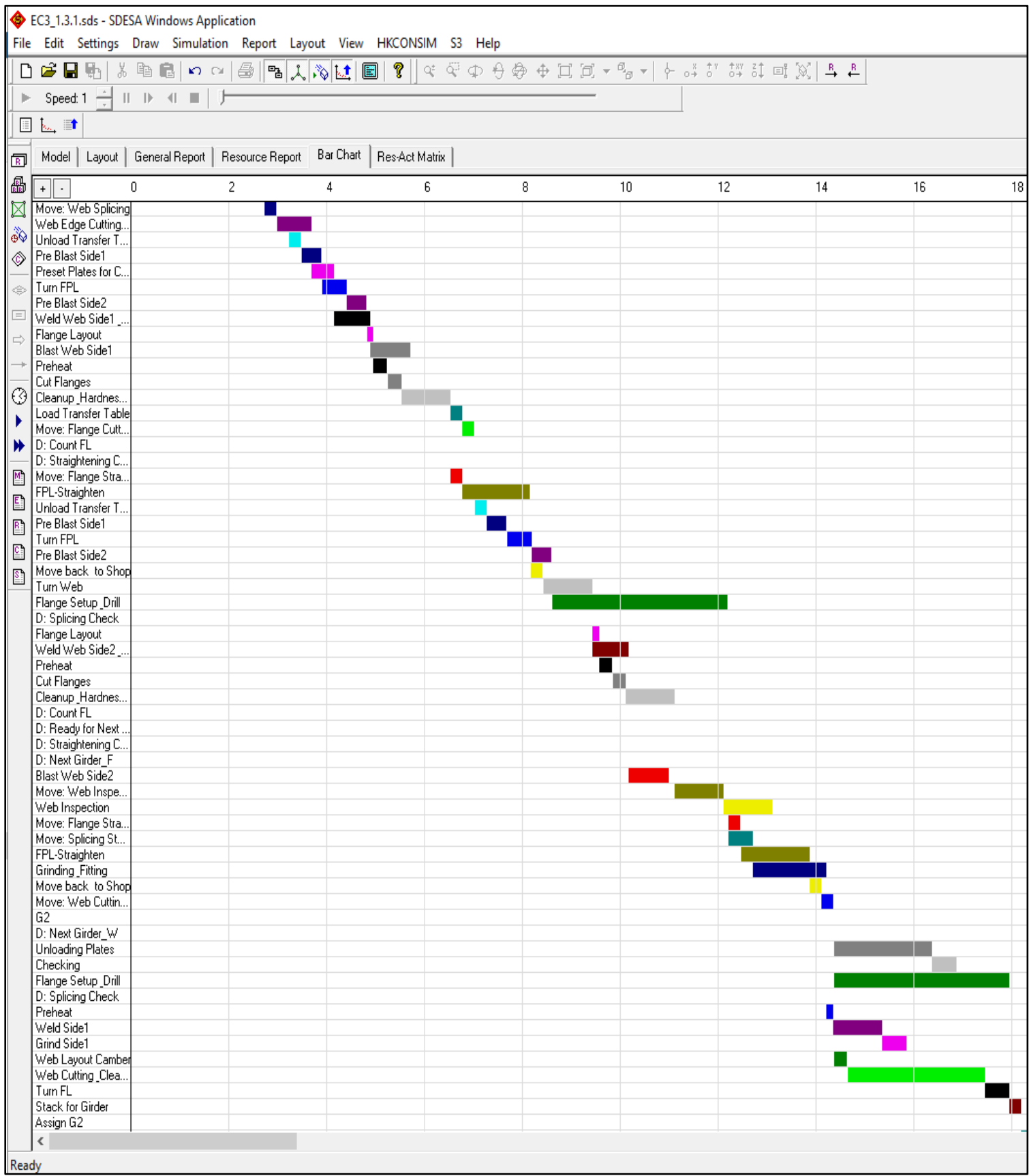

Figure 8 Activity by activity plan for the bridge girder fabrication project (screenshot from SDESA simulation platform)

\begin{tabular}{|c|c|c|c|c|c|c|c|c|c|c|c|c|c|c|c|c|c|c|c|}
\hline Task & & & & & & & & & nuar & & & & & & Febru & 201 & & & \\
\hline Mode - & Task Name & . & Duration & $\checkmark$ & Start & Finish & 23 & 28 & 2 & 7 & 12 & 17 & 22 & 27 & 1 & 6 & 11 & 16 & 21 \\
\hline 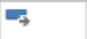 & Girder G1A & & $180 \mathrm{hrs}$ & & Fri $1 / 11 / 19$ & Tue $2 / 12 / 19$ & & & & & & & $1 \mathrm{~A}$ & & & & & & \\
\hline 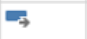 & Girder G1B & & $165 \mathrm{hrs}$ & & Tue $1 / 15 / 19$ & Tue $2 / 12 / 19$ & & & & & & & 1B & & & & & & \\
\hline$=$ & Girder G2A & & 178 hrs & & Thu $1 / 17 / 19$ & Tue 2/19/19 & & & & & & & & & G2A & & & & \\
\hline-5 & Girder G2B & & $138 \mathrm{hrs}$ & & Thu $1 / 24 / 19$ & Tue $2 / 19 / 19$ & & & & & & & & & G2B & & & & \\
\hline-5 & Girder G3A & & $151 \mathrm{hrs}$ & & Thu $1 / 31 / 19$ & Tue $2 / 26 / 19$ & & & & & & & & & & & & G3A & \\
\hline$F$ & Girder G3C & & $116 \mathrm{hrs}$ & & Wed 2/6/19 & Tue 2/26/19 & & & & & & & & & & & & G3B & \\
\hline
\end{tabular}

Figure 9 Timeline for processing individual girder (Schedule for program manager). 
Table 4Task to do list (trade specific) for the first day (11 January 19) for journeyman ID 1.

\begin{tabular}{|c|l|l|l|l|}
\hline ID & \multicolumn{1}{|c|}{ Task Name } & \multicolumn{1}{c|}{ Duration } & \multicolumn{1}{c|}{ Start Time } & \multicolumn{1}{c|}{ Finish Time } \\
\hline 1 & Unloading Plates & $2 \mathrm{hrs}$ & $1 / 11 / 19$ 8:00 AM & $1 / 11 / 19$ 10:00 AM \\
\hline 2 & Move: Web Splicing & $0.25 \mathrm{hrs}$ & $1 / 11 / 1910: 00 \mathrm{AM}$ & $1 / 11 / 1910: 15 \mathrm{AM}$ \\
\hline 3 & $\begin{array}{l}\text { Web Edge Cutting: } \\
\text { Camber }\end{array}$ & $0.7 \mathrm{hrs}$ & $1 / 11 / 1910: 15 \mathrm{AM}$ & $1 / 11 / 1910: 57 \mathrm{AM}$ \\
\hline 4 & $\begin{array}{l}\text { Preset Plates for } \\
\text { Camber }\end{array}$ & $0.47 \mathrm{hrs}$ & $1 / 11 / 19$ 10:57 AM & $1 / 11 / 19$ 11:25 AM \\
\hline 5 & Cut Flanges & $2 \mathrm{hrs}$ & $1 / 11 / 1911: 25 \mathrm{AM}$ & $1 / 11 / 192: 25 \mathrm{PM}$ \\
\hline 6 & $\begin{array}{l}\text { Move to Flange } \\
\text { Straightening Station }\end{array}$ & $0.25 \mathrm{hrs}$ & $1 / 11 / 192: 25 \mathrm{PM}$ & $1 / 11 / 192: 40 \mathrm{PM}$ \\
\hline 7 & FPL-Straighten & $1.4 \mathrm{hrs}$ & $1 / 11 / 192: 40 \mathrm{PM}$ & $1 / 11 / 194: 04 \mathrm{PM}$ \\
\hline 8 & Move back to Shop & $0.25 \mathrm{hrs}$ & $1 / 11 / 194: 04 \mathrm{PM}$ & $1 / 11 / 194: 19 \mathrm{PM}$ \\
\hline 9 & Turn Web & $1 \mathrm{hr}$ & $1 / 11 / 194: 19 \mathrm{PM}$ & $1 / 14 / 198: 19 \mathrm{AM}$ \\
\hline
\end{tabular}

\section{Conclusion}

This paper introduces a simulation-based production planning approach for a structural steel fabrication shop, considering major constraints typically imposed on a fabrication facility simultaneously serving field construction needs from multiple projects. Particular emphasis is placed on representing and interpreting simulated production plans in customized schedules of various details in an attempt to cater for the needs of different stakeholders involved at various management levels. Taking advantage of the developed model of the steel bridge girder fabrication shop, schedules in support of multiple management functions are generated from the simulation. The applicability of the proposed approach is demonstrated with a case in the real-world setting of a steel girder fabrication shop.

Once the job processing sequence along with appropriate resource allocation is determined, project managers simply extract all the necessary plans from the simulation result in the form of customized schedules for various management functions. The Simplified Discrete Event Simulation Approach (SDESA) is used as a platform for dynamic and resource-constrained process mapping and simulation purpose. The shop-floor activity bar chart produced from SDESA simulation shows start to finish for all the activities. However, it is worth mentioning the bar chart schedule in itself is overwhelming for effective communication even if the demonstration case is simplified. One major research contribution is to interpret the bar chart resulting from simulation to the need of different decision makers involved at various management level. As such, production plans based on the same simulation model are represented and communicated in straightforward, role-specific formats (such as "bar charts" or "to-do lists"), thus facilitating execution of different management functions by relevant stakeholders involved.

\section{Acknowledgments}

The research was funded by the National Science and Engineering Research Council (NSERC), and Supreme Group through a Collaborative Research and Development grant (CRDPJ-501012-16). The authors would like particularly to acknowledge Kevin Guile, David Fritz, Arash Mohsenijam, and Chris Ritcey of Supreme Group for providing inputs to problem definition and facilitate validation of this research.

\section{References}

Abourizk, S. M., \& Abourizk, H. (2009). Human Factors and Productivity Improvement. CNRL Natural Resources Engineering Facility, University of Alberta, Edmonton, Canada.

Ahuja, H.A. (1984). Project Management Techniques in Planning and Controlling Construction Projects. John Wiley and Sons, New York, NY.

Chan, W.-H., \& Lu, M. (2008). Materials Handling System Simulation in Precast Viaduct Construction: Modeling, Analysis, and Implementation. Journal of Construction Engineering and Management, 134(4), 300-310.

COAA (2013). Construction Work Packages Best 
Practice: A Consensus. CWP Best Practice Report of Construction Owners Association of Alberta, Canada. Document Number: COP-WFPSPD-16-2013-v1

Dedhia, N. S. (2005). Six Sigma Basics. Total Quality Management, 15 (5), 567-574

Halpin, D., and Riggs, L. (1992). Planning and analysis of construction operations. Wiley \& Sons, Inc., New York.

Harris, R. and Ioannou, P. (1998). Scheduling projects with repeating activities. Journal of Construction Engineering and Management, 124(4), 269-278.

Hendrickson, C. (2008). Project Management for Construction. Carnegie Mellon University, Pittsburgh, PA 15213, Version 2.2. Copyright C. Hendrickson 1998.

Hu, D. and Mohamed, Y. (2014). Simulation-modelstructuring methodology for industrial construction fabrication shops. Journal of Construction Engineering and Management. 140(5), 04014002.

Hyari, K. and El-Rayes, K. (2006). Optimal planning and scheduling for repetitive construction projects. Journal of Management in Engineering, 22(1), 11-19

Liu, J., \& Lu, M. (2018). Constraint Programming Approach to Optimizing Project Schedules under Material Logistics and Crew Availability Constraints. Journal of Construction Engineering and Management, 144(7).

Lu, M. (2003). Simplified Discrete-Event Simulation Approach for Construction Simulation. Journal of Construction Engineering and Management, 129(5), 537-546.

Lu, M. (2009). Job-Sequencing-Resource-Allocation (JSRA) Scheduling Simulation. Proceedings of 16th Annual Canadian Construction Research Forum, Banff, Alberta, Canada 1-14.

Lu, M., Hasan, M. and Mohsenijam, A. (2019). Three-Tiered Simulation Framework for Modeling Bridge Girders Fabrication Processes in a Steel Fabrication Shop. Proceeding of Computing in Civil Engineering Conference 2019, (Accepted)

Lu, N., \& Liska, R. W. (2008). Designers' and general contractors' perceptions of offsite construction techniques in the United States construction industry. International Journal of Construction Education and Research, 4(3), 177188.

Nakhai, B. and Neves, J. S. (2009). The challenges of six sigma in improving service quality. International Journal of Quality \& Reliability Management, 26(7), 663-684

Project Management Institute (2017). A guide to the project management body of knowledge (PMBOK guide), sixth edition, Newtown Square, Pennsylvania.

Pasquire, C.L., and Gibb, A.G.F. (2002). Considerations for assessing the benefits of standardization and pre-assembly in construction. Journal of Financial Management of Property and Construction, 7(3), 151-161

Siu, M. F., Lu, M., and AbouRizk, S. (2013). Improving Sophistication and Representation of Skilled Labor Schedules on Plant Shutdown and Maintenance Projects. Proceedings of the 13th International Conference on Construction Applications of Virtual Reality, 30-31 October 2013, London, UK

Song, L., \& AbouRizk, S. M. (2006). Virtual shop model for experimental planning of steel fabrication projects. Journal of Computing in Civil Engineering, 20(5), 308-3

Warren, R.H. (1989). Motivation and Productivity in the Construction Industry. Van Nostrand Reinhold, New York, NY. 